Check for updates

The BMJ

Cite this as: BMJ 2020;370:m3201 http://dx.doi.org/10.1136/bmj.m3201 Published: 12 August 2020

\section{Covid-19: Healthcare professional is referred to regulator for delaying seeing a patient because of lack of PPE}

\author{
Clare Dyer
}

A healthcare professional is facing a fitness to practise investigation for allegedly delaying attending to a covid-19 positive patient because of inadequate personal protective equipment (PPE), in what may be the first case of its kind.

The revelation came from a healthcare regulatory solicitor, Andrea James, who tweeted, "Was expecting it, but still disgusted to have received first \#FitnessToPractise case arising from NHS trust disciplining healthcare professional who expressed concern about/delayed attending to a Covid+ patient without PPE (NHS Trust having failed to provide said PPE). For shame.”

Doctors and nurses reacted with outrage to the tweet, and the Medical Protection Society issued a strong statement condemning the move. James said that her client wanted to remain anonymous and declined to identify the profession, NHS trust, or regulator involved. She said that the treatment in question was expected to be an aerosol generating procedure.

James, a partner in the law firm Brabners, specialises in defending healthcare professionals before their regulatory bodies, including doctors before the General Medical Council, paramedics before the Health and Care Professions Council, and pharmacists before the General Pharmaceutical Council.

\section{Immunity from investigations}

Rob Hendry, medical director at the Medical Protection Society (MPS), said, "It is appalling enough that healthcare professionals are placed in the position of having to choose between treating patients and keeping themselves and their other patients safe. The stress should not be compounded by the prospect of being brought before a regulatory or disciplinary tribunal.

"MPS members who are faced with regulatory or employment action arising from a decision to not see a patient due to lack of PPE can come to us for advice and representation. However, it should not come to this: healthcare workers should not be held personally accountable for decisions or adverse outcomes that are ultimately the result of poor PPE provision.”

He added, "From the start of this pandemic we have called for healthcare professionals to be afforded immunity from investigations by their employer or the General Medical Council. This case-sadly, probably the first of many covid-19 related cases-demonstrates why this is so important.”

A spokesperson for the MPS said that it had not yet had any such cases involving doctors.

BMA guidance for doctors, updated last month, on refusing to treat in covid-19 cases where PPE is inadequate, states, "You should not face a disciplinary process or detriment if you are confronted with serious and imminent danger in your workplace. We will robustly defend your employment rights to ensure your protection. We recognise that you may be facing a situation where you have to make an urgent decision. Where possible, you should get in touch with us first.

"Remember: there are limits to the risks you can be expected to expose yourself to. You are under no obligation to provide high risk services without appropriate safety and protection. You can refuse to treat patients if your PPE is inadequate, you are at high risk of infection and there is no other way of delivering the care."

We amended this news item on 13 August 2020 following a request from Brabners LLP.

This article is made freely available for use in accordance with BMJ's website terms and conditions for the duration of the covid-19 pandemic or until otherwise determined by BMJ. You may use, download and print the article for any lawful, non-commercial purpose (including text and data mining) provided that all copyright notices and trade marks are retained. 